the tendency of the blood-mass to increase in cases of chronic heart failure. After pointing out that the primary effect of cardiac failure is to lower capillary pressure he insists on the clinical fact that there is often evidence of high capillary pressure in uncompensated heart disease. How are these facts to be reconciled? "The clue to this difficulty is," he believes, "to be found in the fact that all cases of uncompensated cardiac lesions are associated with hydræmic plethora. This association has been shown actually to exist by the observations of Stintzing and Gumprecht. I wish, however, to show you," continues Dr. Starling, " that such a condition of hydræmic plethora must be an inevitable physiological consequence of the failure of the heart pump. We have just seen that heart failure causes a fall of ...... capillary pressure. This fall, like that consequent on artificial anæmia, will disturb the relationship between the blood and the lymph; there will be an absorption of lymph from the tissue spaces-the blood will be increased in volume." I had myself already come to the conclusion that the blood-mass tends to be augmented in chronic heart failure, and as this is a point of considerable practical interest to the physician I may perhaps be permitted to quote from an unpublished manuscript (written some two years since) in which my reasons for this conclusion are set forth. "In many cases of passive congestion of the lungs and systemic veins, or of the latter alone, the volume of blood is, I believe, increased. It is evident that an accumulation of blood in these parts must, unless the blood-mass be augmented, lead to a depletion of the systemic arteries and a defective supply to the capillaries, causing a fall of capillary blood pressure. So far as these latter vessels are concerned, the effect of transferring for any length of time a portion of blood which should be in the arteries to the veins is much the same as removing that amount of blood from the body. In each case the essential result is a diminution in the quantity of blood passing through the capillaries, the diminution being actually greater in passive venous engorgement than from bleeding owing to the circulatory defect accompanying the former condition. Now, after bleeding the blood tends to regain its wonted quantity and quality, the organism appreciating the loss by reason, we may suppose, of the capillary dearth of blood, and one would expect the same kind of thing to happen when the individual bleeds into his systemic veins and pulmonary vessels. This conclusion is supported by clinical observation. While passive venous engorgement is often accompanied by emptiness of the systemic arteries, as shown by the smallness of the radial pulse, this is by no means always the case. Sometimes the radial artery is quite large and there is every evidence of arterial plethora, which would be impossible were there no increase in the total volume of blood. Again, in marked venous engorgement there would sometimes appear to be high capillary pressure, as shown by a florid complexion and a copious urinary flow, and it would be impossible to get this were the arteries defectively supplied with blood, as would happen if its mass were not augmented." It will be observed from this passage that I go even further than Dr. Starling, holding, as I do, that the increase in the blood referred to is not merely a watery increase, but that the solid constituents of the blood are at the same time augmented, though doubtless hydræmia is often observed.

The degree of augmentation of the blood mass consequent upon heart failure differs greatly in different cases. I have now under observation two patients presenting extremes in this respect. The one has great distension of the superficial vessels of the face; his radial artery is large and tense, and if he allows his hand to hang down by the side of the bed it rapidly becomes odematous. In this case capillary pressure is high and the volume of blood must be considerably augmented. The other patient, who has an enormously dilated heart, is anæmic in appearance; his radial pulse is very small and scarcely perceptible, only one out of erery three heart beats being felt at the wrist. It is clear that in this case capillary pressure is low, and it is probable that the blood-mass is not greatly augmented. I may observe that the tendency to dropsy in this patient is less than in the other, and this bears out Sir William Broadbent's suggestion that cardiac dropsy is more apt to occur when arterial tension is well maintained than when it is very low, a conclusion, by the way, in entire keeping with Dr. Starling's teachings as to the causation of cardiac dropsy.

Devonshire-street, $\mathbf{w}$. I am, Sirs, yours tr

HARRI CAMIPBELL.

\section{"THE PRETALENCE OF DIPHTHERIA IN CONNEXION WITH ELEMENTARY SCHOOLS."}

To the Editors of THE LAxCET.

SiRs,-I shall be obliged if you will grant me space to make a few comments upon the article which appeared in THE LANCET of May 23rd relative to a report which I have recently presented to the School Board for London in response to the following resolution: "That the medical officer be requested to report generally on the prevalence of diphtheria in London and elsewhere, and its alleged connexion with the elementary schools, and, further, to adrise what, if any, steps the Board should take in the matter."

You are in error in implying that this resolution was arrived at consequent upon the publication of any memorandum by Mr. Shirley Murphy. The notice of the Board had on several occasions been drawn to the increasing prevalence of diphtheria in London and the opinion which had been expressed by various writers, amongst them Mr. Shirley Murphy, of the possible agency of the schools in spreading the disease ; and for these reasons the above resolution was passed. In the course of my report I had occasion to refer to the observations of certain writers, and in this way to those of Mr. Shirley Murphy; but in your article the whole question is made apparently to revolve round the personality of that gentleman. I note that you think Part I. of the report, which deals with the geographical distribution of the disease since 1861, although "interesting," is not " relevant" to the question. But why? Elementary schools are found all over the country; diphtheria is not, scarlet fever is not, and measles is not; doubtless all these diseases are sometimes communicated in schools, as they are sometimes in churches, children's parties, \&c. But if schools are the main cause or even a principal cause of the diffusion of infectious diseases, why, may I ask, do the schools select diphtheria in Sussex and measles in Staffordshire? Should not the words "not ..... relevant" contained in your article be read " not convenient"? for questions like these would appear very important to the enquiry, "How much do elementary schools have to do with the selection and diffusion of the different zymotics that prevail in different localities"? and they point to the fallacy of assuming that when the schools have been denounced the last word has been said. The comparison which I made between $1881-90$ and $1871-80$ is a perfectly right one. The question for me to consider was, When diphtheria increased in 1881-90 how did it affect different ages? Other factors beside school attendance would have been present in making a comparison with a more distant period, the character of the disease might have changed, certainly the conditions of housing had altered, sc.

I see that a somewhat adroit manipulation of figures is suggested by the writer of the article to enable him to escape. from the difficulty in which he finds himself. I have constructed, however, the following table :--

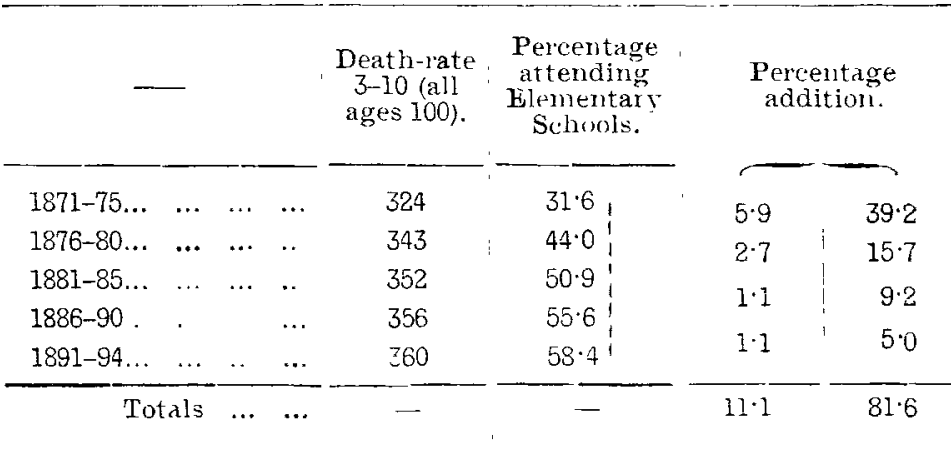

From this it will be seen that in 1891-94, as comparecl with $1871-75$, there is an addition of 81.6 per cent to the number of children attending school, and at the same time there was an addition of $11 \cdot 1$ to the diphtheria rate compared with that at all ages. I hare admitted that children do sometimes contract diphtheria at schools, and apparently the effect of nearly doubling the school attendance is to add 11 per cent. to the risk of diphtheria calculated in this way. I regret that something like a sneer is sought to be conveyed in your criticism of my use of the Asylums Board nurses and teachers of the School Board. It would appear impossible to carry out an inquiry into school influence without the aid of the latter, and $I$ 
"venture to think the services of the nurses were also of a most valuable kind; at any rate, comfort is songht for Mr. Murphy in the result of the investigation, which shows only 7.6 per cent. of the cases to be possibly attributable to school influence, "a complete justification of the position which he has assumed" being found therein. One is tempted to ask, what about the origin of the remaining trifle of 92.4 per cent. of the cases? That the schools are not to blame for the great increase of diphtheria in London I am convinced, and the sooner we abandon this unstable view and set to work to find out the real cause the better for science and the better for the metropolis.

$$
\text { I am, Sirs, yours faithfully, }
$$

June 8th, 1896.

WILLIAM R. SMith, M.D. Aberd.

** The space at our disposal does not permit us to do more than comment briefly on the matter referred to in Dr. Smith's letter. We must be pardoned if we have assumed that his report is intended as a reply to the reports of Mr. Shirley Murphy, seeing that of the pages in Dr. Smith's report which we can regard as relevant to the subject of the influence of schools on diphtheria prevalence at least three-quarters are devoted to a criticism of Mr. Murphy's two points-(1) the change in the age incidence of diphtheria mortality since 1870 ; and (2) the reduction in the number of notified cases of diphtheria at the time the London board schools are closed for the summer holidays. Dr. Smith's remarks concerning the comparisons of the decades 1871-80 and 1881-90 make it evident that he still fails to see that a change effected in the main in the decade 1871-80, and conspicuous when comparison is made between 1861-70 and 1871-80, need not (to meet the school hypothesis) be again conspicuous between 1871-80 and 188190. We pass by Dr. Smith's incomprehensible reference to a "somewhat adroit manipulation of figures" by the writer of our article "to enable him to escape from the difficulty in which he finds himself." The table in Dr. Smith's letter leads us to the conclusion that he is now prepared to abandon the position he assumed in his report when he wrote " that while the percentage of children attending elementary schools has largely increased-viz., from 24.8 per cent. in 1871 to 59.8 per cent. in 1893 - the comparative death-rate at ages three to ten has remained throughout these years fairly constant." As Dr. Smith now evidently sees, it has done nothing of the sort; but, as we pointed out in our article, "with increase of school attendances there has been a gradual increase of comparative diphtheria mortality at the school ages." In studying these figures there is, however, another consideration which must be held in view, and that is that the diphtheria rate at $3-10$ compared with all ages does not make evident the whole story of the increased incidence of the diphtheria rate on that age. The result is masked and greatly minimised by the fact that the deaths from 3-10 constitute a very large proportion of the deaths at all ages. The comparison, therefore, between the increase of 11.1 per cent. in the comparative death-rate and the increase of 81.6 per cent. in the proportion of the children attending school is absurd. How much of the increase in the death-rate at all ages is due to increased school attendance still remains unknown, and certainly we are not prepared to accept Dr. Smith's 7.6 per cent. of the cases at school age as including anything like all which are "possibly attributable to school influence." Dr. Sraith concludes his letter by stating that "schools are not to blame for the great increase of diphtheria in London." We challenge him to refer us to the statement of any person who has said they are. There is a wide difference between the position which regards schools as contributing in important degree to this increase and that which regards schools as the sole factor in such increase. All the evidence at present available points to the inaccuracy of Dr. Smith's conclusion that school influence "plays but an unimportant part" in the increase.-ED. L.

\section{THE CASE OF MR. LIONEL SMITH.} To the Editors of THE LANCET.

SIRs,--Will you allow me through your columns to thank those gentlemen who so kindly came forward to assist me out of the difficulties in which I was placed by the action of the West Australian Government? I have now reached my new home and I hope to make a fresh and successfu start in life which, but for the generous aid accorded me, I should have been unable to accomplish.

I am, Sirs, yours faithfully, H. LIONEL SirTH.

N'Qutu, Zululand, South Africa, May 11th, 1896.

\section{ISOLATION AND THE PUBLIC HEALTH ACT,}

\section{To the Editors of THE LANCET.}

SIRs,-The following matter, which I will put as briefly as possible, may be of interest and use, perhaps, to some of your readers. Since the introduction of "notification" by the Public Health Act (London), 1891, I have had some trouble with the sanitary authority of this parish of St. George, Hanover-square. During this period it has been the custom to remove as many as possible of the cases of scarlet fever and diphtheria to the Metropolitan Asylums Board Hospitals. Certain cases, however, which I have me with in my practice $I$ have decided, for reasons stated below, to retain and attend at their own homes, and have expressed to the patients' relatives my approval that they should so remain, provided that my directions as to isolation and treatment were faithfully carried out, and therefore they could remain. Notwithstanding this, and knowing that I had expressed this opinion, the sanitary inspector has stepped in, has insisted on the patients being removed to the hospital and they have been so remored, the grounds given for this action being that the patients were not properly isolated in his opinion.

The cases in question were mostly scarlet fever or diphtheria, occurring in families occupying generally three or four, sometimes only two, rooms; but in each case the patient was put into a separate room from the rest and confined there without any direct communication with other members of the family, the only person going backwards and forwards at all from the sick room being the nurse-usually, of course, the child's mother-whom I made take sufficient precautions against spreading the disease. I have attended many such cases in pre-notification years and have nerer known the disease to spread after such isolation has been established in any case. Now the question of what is proper isolation is, I maintain, essentially a medical question, and it is intolerable that an unqualified person, such as a sanitary inspector, should be allowed to override the opinion of a medical man on a medical question or to interfere with his patients, nor is it professionally correct for a medical officer of health to disregard the opinion of another medical man. I complained more than once to the medical officer of health (Dr. Corfield), but he supported the sanitary inspector and the offence was repeated. The Public Health Act is not very definite on the matter; but as it declares that any legally qualified medical practitioner may certify that an infections patient has not proper accommodation one would suppose (and this seems to agree with common sense) that he would be equally able and entitled to certify the obverse-viz., that an infectious patient was properly accommodated and isolated. I therefore wrote to the Local Government Board last February, stating the case and giving particulars, and asked for an authoritative opinion. The Local Gorernment Board corresponded with the sanitary authority of St. George's, Hanover-square, and replied to me on the 2 nd inst., enclosing a copy of the Board's final reply to the Vestry, as follows:-

Local Government Board, Whitehall, S.W., March 28th, 1896. To the Clerk of the Vestry, St. George's, Hanover-square. SIR,-I am directed by the Local Government Board to acknowledge the receipt of your letter of the 18th inst. enclosing a copr of a report which the Vestry of the Parish of St. George, Hanover-square, have receivel from their medical officer of health respecting the complaint of Dr. Benbam, and in reply I am to state that whilst the Board concur with the riew expressed by the medical officer of health as to the desirability of securing isolation in hospital of such cases of the infectious fevers as are referred to in his report, they are of opinion that where a medical practitioner is known to be in attendance on any such case, removal to hospital by the officers of the sanitary authority 